\title{
Valuing the Ozone-Related Health Benefits of Methane Emission Controls
}

\author{
Marcus C. Sarofim ${ }^{1}$ • Stephanie T. Waldhoff ${ }^{2}$ • \\ Susan C. Anenberg 3
}

Accepted: 11 June 2015 / Published online: 29 June 2015

(C) The Author(s) 2015. This article is published with open access at Springerlink.com

\begin{abstract}
Methane is a greenhouse gas that oxidizes to form ground-level ozone, itself a greenhouse gas and a health-harmful air pollutant. Reducing methane emissions will both slow anthropogenic climate change and reduce ozone-related mortality. We estimate the benefits of reducing methane emissions anywhere in the world for ozone-related premature mortality globally and for eight geographic regions. Our methods are consistent with those used by the US Government to estimate the social cost of carbon (SCC). We find that the global short- and long-term premature mortality benefits due to reduced ozone production from methane mitigation are (2011) \$790 and \$1775 per tonne methane, respectively. These correspond to approximately 70 and $150 \%$ of the valuation of methane's global climate impacts using the SCC after extrapolating from carbon dioxide to methane using global warming potential estimates. Results for monetized benefits are sensitive to a number of factors, particularly the choice of elasticity to income growth used when calculating the value of a statistical life. The benefits increase for emission years further in the future. Regionally, most of the global mortality benefits accrue in Asia, but $10 \%$ accrue in the United States. This methodology can be used to assess the benefits of methane emission reductions anywhere in the world, including those achieved by national and multinational policies.
\end{abstract}

Marcus C. Sarofim, Stephanie T. Waldhoff and Susan C. Anenberg have contributed equally to this work.

Marcus C. Sarofim

Sarofim.marcus@epa.gov

Stephanie T. Waldhoff

Stephanie.waldhoff@pnnl.gov

Susan C. Anenberg

susan.anenberg@airhealthanalytics.com

1 U.S. Environmental Protection Agency (USEPA, 6207A), 1200 Pennsylvania Ave NW, Washington, DC 20460, USA

2 Joint Global Change Research Institute, Pacific Northwest National Laboratory, College Park, MD, USA

3 Environmental Health Analytics, LLC, Washington, DC, USA 
Keywords Methane $\cdot$ Ozone $\cdot$ Mortality $\cdot$ Air pollution $\cdot$ SCC

\section{Introduction}

Methane $\left(\mathrm{CH}_{4}\right)$ is a relatively short-lived and potent greenhouse gas. It also reacts in the atmosphere to form ground-level ozone $\left(\mathrm{O}_{3}\right)$ that is itself is a greenhouse gas as well as a pollutant that is associated with adverse health effects such as impaired respiratory health and premature mortality (US Environmental Protection Agency 2012) and damaged vegetation. Methane is emitted by natural sources, such as wetlands, and anthropogenic sources, such as agriculture, coal mines, municipal solid waste, oil and gas systems, and wastewater. Anthropogenic activities contribute approximately $50-65 \%$ of total global methane emissions (IPCC 2013).

While methane has long been considered to be an important greenhouse gas to target for climate change mitigation and is included in the basket of climate pollutants under the United Nations Framework Convention on Climate Change (UNFCCC), it has only recently been appreciated as a potential method to control surface ozone concentrations (West et al. 2006). Two voluntary international efforts, the Climate and Clean Air Coalition to Reduce ShortLived Climate Pollutants ${ }^{1}$ (CCAC) and the Global Methane Initiative, ${ }^{2}$ aim to reduce methane emissions from anthropogenic sources. Many national efforts that achieve methane emission reductions as a primary target or as a co-benefit are also underway, including regulations like the Oil and Natural Gas Air Pollution Standards and voluntary programs like the Natural Gas STAR Program, the AgSTAR Program, and the Landfill Methane Outreach Program in the US Given the many methane mitigation activities ongoing at international and national scales, valuing both the climate and health benefits of national and international actions to control methane emissions ${ }^{3}$ can inform policy decision-making.

Although the 12-year methane lifetime is shorter than that of many greenhouse gases (e.g., $\mathrm{N}_{2} \mathrm{O}$ has a lifetime of 110 years, chloro- and perfluoro-carbons lifetimes of thousands of years, and while $\mathrm{CO}_{2}$ doesn't have a single lifetime, it is added to the carbon cycle for millennia), it lives longer in the atmosphere than the other major ozone precursors (nitrogen oxides, nonmethane volatile organic compounds, and carbon monoxide), with atmospheric lifetimes on the order of weeks or months depending on the gas (IPCC 2007). Ozone is formed as product of the methane oxidation process, and as a result, ozone production via methane occurs on the same decadal time scale as methane's lifetime, long enough to be globally well-mixed in the atmosphere [e.g., (West et al. 2006)]. Therefore, the ozone response to methane emission reductions is mostly insensitive to the location in which the emissions were reduced (ibid). The relative uniformity of the ozone response to methane emissions allows for the quantification of ozone benefits for a particular location per tonne of methane emission reduced anywhere in the world. Similarly, the climate benefits of marginal reductions in methane, known as the Social Cost of Methane $\left(\mathrm{SC}-\mathrm{CH}_{4}\right)$ have been estimated in the literature [e.g. (Marten et al. 2014; Marten and Newbold 2012; Waldhoff et al. 2014)]. The US Government has also calculated benefits of methane reduction using the Social Cost of Carbon ${ }^{4}$ (SCC) and

\footnotetext{
1 www.unep.org/ccac.

2 https://www.globalmethane.org/.

3 Throughout this paper we refer to the benefits of methane mitigation, though our estimates are equally valid to estimate the damages of increases in $\mathrm{CH}_{4}$ emissions. For simplicity, we restrict our language to focus on the benefits of mitigation.
}

4 The SCC, as used by the US Government, is valued in units of $\$ / t-\mathrm{CO}_{2}$. 
the Global Warming Potential (GWP) of methane. Using a GWP of 25 (IPCC 2007) yields climate change benefits of (2011) $\$ 1,150 / \mathrm{t}-\mathrm{CH}_{4}$ in 2020. The global ozone mortality benefits of methane mitigation estimated in this paper are of similar magnitude to the monetized climate benefits of methane mitigation. As we refer to it in this paper, the "social cost" of methane refers only to the climate impacts, though the term could be used to refer to all the impacts of methane including the health and agricultural impacts resulting from methane oxidation. A cost-benefit analysis can then be done by comparing these marginal benefits$\mathrm{SC}-\mathrm{CH}_{4}$ and ozone-related mortality - to the marginal cost of an emission control strategy.

Previously, studies have used global chemical transport modeling to estimate the premature mortality impact of ozone reductions resulting from large reductions in methane emissions or concentration. These studies estimated that reductions of $20 \%$ in anthropogenic methane emissions (West et al. 2006) or in methane concentrations (Anenberg et al. 2009) would result in about 17,000 global premature ozone-related cardiopulmonary deaths avoided (and 1.7 times that number of total avoided non-accidental deaths), or about 150-260 cardiopulmonary deaths avoided per $\mathrm{Mt} \mathrm{CH}_{4}$ reduced. Using similar methods but focusing on long-term ozone concentration-mortality relationships, further implementing seven specific methane emission control measures around the world was also estimated to avoid 47,000 premature deaths annually in 2030 , or about 340 deaths avoided valued at approximately $\$ 1,000 /$ tonne of methane emission reduced (Anenberg et al. 2012; Shindell et al. 2012).

The approach taken here has been designed to produce monetized benefits of reductions that are consistent with the methodology used for development of the US Government calculations of the SCC. In addition, this approach is novel in comparison to previous analyses that quantify the ozone-related health impacts of $\mathrm{CH}_{4}$ reductions in that it estimates avoided respiratory mortality associated with mitigating a marginal tonne of $\mathrm{CH}_{4}$ emissions in a given year.

The paper proceeds as follows. Section 2 presents the methodology and sources used to estimate the indirect health benefits of $\mathrm{CH}_{4}$ mitigation. Section 3 presents the results and discussion of multiple sensitivity tests on the short-term mortality estimates, as well as estimated benefits of $\mathrm{CH}_{4}$ mitigation on long-term $\mathrm{O}_{3}$-related mortality. Section 4 concludes.

\section{Methods}

The approach taken here begins by calculating avoided respiratory mortality over several decades associated with mitigating a marginal tonne of $\mathrm{CH}_{4}$ emissions in a given year. The mortality reduction is then valued and discounted back to the year of emissions. The result is a value that is well suited to regulatory analysis, enabling the estimation of the ozone-related mortality benefits of policies that reduce $\mathrm{CH}_{4}$ emissions.

Our method makes use of the existing literature on the relationships between $\mathrm{CH}_{4}$ emissions and $\mathrm{O}_{3}$ concentrations, changes in $\mathrm{O}_{3}$ concentrations and short-term mortality, future scenarios of population and income, and the value of lives lost. The roles of each of these on the estimates are described in turn below.

\subsection{Methane Emissions and Ozone Concentrations}

The analysis begins with an instantaneous pulse of 1 tonne of methane. This methane is assumed to have a lifetime of 12 years, consistent with the perturbation lifetime from the IPCC AR4 (IPCC 2007). We consider the effect of 1 tonne of methane on short- and longterm ozone exposure metrics (annual average ozone for short-term and the 6 month average of the $1 \mathrm{~h}$ daily maximum ozone for long-term, consistent with the epidemiology studies 
from which ozone-mortality relationships were derived, as described below). We derive the 24-h average surface ozone response to an elevated atmospheric loading of methane from (Fiore et al. 2008), who estimated a response of $11-15$ ppt $\mathrm{O}_{3}$ as a steady state response to $1 \mathrm{Tg}$ reduction in annual methane emissions. Using a mean response of $13 \mathrm{ppt}_{3}$ and taking into account the fact that at steady-state $1 \mathrm{Tg}_{\text {year }}{ }^{-1}$ of methane is equivalent to $12 \mathrm{Tg}$ of atmospheric methane loading, we calculate the ozone response in year t to a $1 \mathrm{Tg}$ pulse of methane at time zero to be

$$
\Delta \mathrm{O}_{3}(\mathrm{t})=13 / 12^{*} \exp (-(\mathrm{t}) / 12)
$$

The April-September average of the 1-h daily maximum ozone concentration response to an elevated atmospheric loading of methane is derived from a 3.0 to $3.6 \mathrm{ppb}$ change as a steady-state response to a $139 \mathrm{Tg}$ reduction in annual methane emissions (Anenberg et al. 2012). We use a 70 year timeframe, capturing more than $99 \%$ of the total integrated methane loading over all time.

\subsection{Ozone-Mortality Concentration-Response Relationships}

We use epidemiologically-derived health impact functions to estimate changes in both premature short-term respiratory mortality related to transient changes in ozone concentration and longer-term mortality from chronic exposure to peak ozone concentrations in response to a pulse of methane emissions.

To estimate the mortality impacts we assume log-linear relationships between ozone concentration and relative risk, following (Anenberg et al. 2010). The fraction of baseline deaths attributable to a given change in concentration (attributable fraction, AF) is:

$$
\mathrm{AF}=(\mathrm{RR}-1) / \mathrm{RR}=1-\exp \left(-\beta \Delta \mathrm{O}_{3}\right)
$$

where $\beta$ is the slope of the log-linear relation between ozone concentration and mortality (concentration-response factor) and $\Delta \mathrm{O}_{3}$ is the change in ozone in response to a pulse of methane emissions. AF is multiplied by the baseline cause-specific mortality rate $\left(\mathrm{y}_{0}\right)$ and population size (pop) to estimate the change in mortality ( $\Delta$ Mort) associated with a given change in concentration:

$$
\Delta \text { Mort }=\mathrm{y}_{0} \times \text { pop } \times\left(1-\exp \left(-\beta \Delta \mathrm{O}_{3}\right)\right.
$$

Equation 3 is applied in each world region using the corresponding population size, baseline mortality rate, and change in ozone concentration.

We quantify ozone-mortality impacts using two different ozone exposure metrics found by the epidemiological literature to be associated with premature mortality: daily exposure ("short-term") and repeated exposure to hourly peak concentrations over the warm season ("long-term"). For short-term exposure, we calculate $\beta$ from the (Bell et al. 2004) study of 95 US urban communities, who found that a $10 \mathrm{ppb}$ increase in 24-h average ozone was associated with a $0.64 \%$ (95\% posterior interval, $0.31-0.98 \%)$ increase in cardiovascular and respiratory mortality. For long-term mortality, we calculate $\beta$ from the (Jerrett et al. 2009) study of the American Cancer Society study cohort of adults aged 30 and older. We use the two pollutant model that controlled for fine particulate matter (PM2.5), which found that a $10 \mathrm{ppb}$ increase in the April-September average of the 1-h daily maximum ozone concentration was associated with a $4 \%$ (95\% confidence interval, 1.0-6.7\%) increase in respiratory mortality. Following (Anenberg et al. 2010, 2012), we apply these concentration-response relationships found in the US globally, despite differences in exposure, susceptibility, and vulnerability 
around the world. We focus on cause-specific mortality since it is more comparable among populations in different countries than is all-cause mortality.

\subsection{Future Population Projections}

To estimate the changes in mortality over time due to a reduction in $\mathrm{CH}_{4}$, it is necessary to project population (Eq. 3, pop) and baseline mortality (Eq. 3, $\mathrm{y}_{0}$ ) over the coming century. While a number of long-term projections for global population exist, e.g. (Nakicenovic 2000; United Nations 2004), in order to promote consistency and comparability with the SCC approach, the same scenarios used by the US Government in developing and updating the SCC (US Department of Energy 2010; US Government 2013) are used here. ${ }^{5}$ These scenarios are Business as Usual (BAU) simulations from four integrated assessment modelsMiniCAM, MESSAGE, MERGE, and IMAGE - that participated in the Energy Modeling Forum 22 (EMF 22) exercise (Clarke et al. 2009). The population for each of the four models' scenarios is aggregated to eight global regions as described in (US Department of Energy 2010). Our base estimate uses the MiniCAM scenario and the other three scenarios are used to test the sensitivity of the results to changes in population and GDP.

We estimate the effects of long-term exposure to peak ozone concentrations only for the population ages 30 and above, consistent with the American Cancer Society cohort used by Jerrett et al. (2009). In order to generate this value for each of the four socioeconomic scenarios, we first estimated the fraction of the population in this demographic using UN country-level population projections (United Nations 2004) by age category and then aggregated to our eight regions. We then applied this ratio to the total population for each of our four socio-economic scenarios. ${ }^{6}$

\subsection{Future Baseline Mortality Rates}

Our methodology to estimate mortality due to ozone concentrations changes also requires baseline rates of death due to cardiovascular and respiratory disease for the total population and respiratory disease for the population age 30 and above.

These rates vary greatly by region and would be expected to change over time as economies develop and mortality rates shift from infectious disease to chronic disease. This type of information is not included in the EMF 22 scenarios used for the SCC estimation. Country-level projections of total cardiovascular and pulmonary deaths through $2100^{7}$ [International Futures Project (IFs) base projections (International Futures 2013)] are aggregated to the eight regions corresponding to the population and GDP scenarios, weighted by 2004 country population and cardiovascular and pulmonary death rates (Mathers et al. 2008). We apply these baseline death rates to all socio-economic scenarios. We test the

5 The SCC estimates were developed using the four models' BAU scenarios, plus a fifth set of parameters that are the averages of these four models' population, GDP, and non- $\mathrm{CO}_{2}$ emissions for a GHG mitigation policy case. Because the estimation of damages from $\mathrm{CH}_{4}$ emissions is linearly related to population and GDP, and does not depend on background concentrations (and therefore emissions) of GHGs, the results from this fifth set of parameters would be a simple average of the four scenarios being used here and is therefore not included.

6 Although scenarios with different total populations in 2100 are likely to have differing fractions of the population in the age 30 and above category, detailed demographic projections are not available for the individual scenarios. Thus these values should be interpreted as a sensitivity test of the total number of individuals in the demographic category, rather than a specific scenario projection.

7 The timeframe for analysis is 70 years, so emissions in the years 2040 and 2050 require baseline death rates through 2110 and 2120, respectively. We hold death rates constant at 2100 levels through 2120 . 
sensitivity of the results to baseline mortality rates using constant 2010 baseline mortality rates.

Estimating long-term ozone mortality impacts requires baseline respiratory mortality rates for the subset of the population ages 30 and above. We first use the Global Burden of Disease (Lim et al. 2012) ${ }^{8}$ country-level, ages 30+, respiratory mortality rates for 2010, weighted and aggregated to the eight regions, then approximate annual rates through 2100 by scaling 2010 respiratory mortality with the cardiovascular and pulmonary mortality rates from the IFs. We also test the sensitivity of results to constant 2010 mortality rates.

\subsection{Valuation of Changes in Mortality}

In order to monetize the reduction in mortality estimated above, we apply a Value of Statistical Life (VSL) to the change in mortality in each future year. These values are then discounted back to the year of emission and summed, producing a Net Present Value (NPV) of the indirect health benefits of $\mathrm{CH}_{4}$ mitigation, measured in (2011)\$/t- $-\mathrm{CH}_{4}$.

Since present and future estimates of VSL for every country or region are not available, we test the sensitivity of results to three methods of extrapolating the VSL. Each method is anchored to the value used by the US Environmental Protection Agency for the US VSL (US Environmental Protection Agency 2010) and then extrapolated across region and time by assuming an elasticity $(\varepsilon)$ of the VSL to income:

$$
\mathrm{VSL}_{\mathrm{x}, \mathrm{t}}=\mathrm{VSL}_{\mathrm{ref}, 0}{ }^{*}\left(\text { Income }_{\mathrm{x}, \mathrm{t}} / \text { Income }_{\mathrm{ref}, 0}\right)^{\varepsilon}
$$

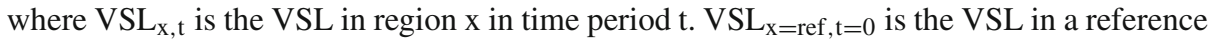
region and year. In this case we reference to the EPA VSL in the US in 2010, adjusted to 2011\$, of $\$ 8.84$ million per premature death. Income is defined in $2011 \$$ per capita, ${ }^{9}$ and estimated using GDP and population data from the EMF 22 scenarios (income = GDP/population). Three elasticity sensitivities are used in this study: 0.0, 0.4, and 1.0. The elasticity of 0.4 , which is used in our base health benefit estimate, is used by (Shindell et al. 2012). An elasticity of 0 generates a VSL that is constant across region and time and equal to the US 2010 VSL of (2011)\$8.84 million, while an elasticity of $1.0^{10}$ produces a VSL that is proportional to income. While an elasticity of 1.0 is the largest elasticity considered in this study, there are some studies that indicate that the income elasticity may be greater than 1 in some cases (Hammitt and Robinson 2011).

The total annual value of reduced mortality must be discounted back to the year of emissions in order to calculate the NPV. Estimates of benefits that accrue over long time horizons (such as the SCC) are highly sensitive to the discount rate. We therefore test seven discount rate estimates. The first four are constant discount rates of 2.5, 3.0, 5.0, and 7.0\%. The first three correspond to the discount rates used to develop the US SCC estimates and 3 and $7 \%$ correspond to the discount rates of consumption and capital as used in US regulatory analyses (US Office of Management and Budget 2003).

Three additional sensitivities, using a Ramsey discounting framework in which the growth rate of income in a given region and period influence the discount rate, are also tested. The

\footnotetext{
8 Data are available at http://www.healthmetricsandevaluation.org/.

9 All values are in 2011\$ unless otherwise noted. GDP data for the EMF 22 scenarios is in $2005 \$$ and is adjusted to $2011 \$$ using a multiplier of 1.0608 .

10 This is the value utilized by the FUND model (Anthoff and Tol 2013), which is one of the three models used to develop the US Government's SCC estimate.
} 
Ramsey discounting framework (Eq. 5) decomposes the discount rate into two parts:

$$
\mathrm{r}_{\mathrm{x}, \mathrm{t}}=\rho+\eta * \mathrm{~g}_{\mathrm{x}, \mathrm{t}}
$$

where $r_{x, t}$ is the discount rate for region $x$ in time period $t, \eta$ is the marginal utility of consumption, and $g_{x, t}$ is the income growth rate in that region and period. The "pure rate of time preference," $\rho$, represents a strict preference for a dollar today over a dollar tomorrow and the elasticity of the marginal utility of consumption times the GDP growth rate, $\eta^{*} g_{x, t}$, has the effect of increasing the discount rate for rapidly growing economies. When the rate of growth is constant across all regions and periods, the Ramsey formula will result in a constant value. In shorter-term, regional analyses, a constant discount rate may be a reasonable approximation. The Ramsey formula is more appropriate when growth rates vary greatly over time and across regions. We test the sensitivity of our results to the Ramsey discount method with three additional discount rates. There is no clearly agreed upon value for $\rho$, and very low values, like $0.1 \%$ have been used in valuing long-term climate damages, though $1 \%$ is a more common value and estimates up to $3 \%$ have also been used. These three estimates of $\rho$ and $\eta=1$ are used to estimate the three Ramsey discounting sensitivity tests.

The base estimates for both short- and long-term ozone-related mortality due to a 1 tonne change in methane are calculated using an emission year of 2020, the MiniCAM scenario inputs for population and GDP, average $\Delta \mathrm{O}_{3}$, central estimates of $\beta$, the IFs baseline for $\mathrm{y}_{0}$, and a constant discount rate of $3 \%$. We test the sensitivity of the ozone-related mortality benefits of a reduction of a marginal tonne of methane over all input parameters. These include four additional estimates of the attributable fraction of mortality from methane emissions, including both a high and low estimate of $\Delta \mathrm{O}_{3}$ and the bounds of the 95 percentile range estimate of $\beta$, an alternate specification of $\mathrm{y}_{0}$, GDP and population from three additional socioeconomic scenarios, six additional discount rates, two additional methods of VSL estimation, and four other years of emission.

\section{Results and Discussion}

Our base estimate ${ }^{11}$ of the global avoided premature cardiovascular and pulmonary deaths due to short-term peak ozone exposure, over a 70 year period, due to a one million tonne decrease in methane emissions in 2020, is 239 deaths, with a monetized value of (2011)\$790/t- $\mathrm{CH}_{4}$. We estimate that a one million tonne decrease in methane emissions in 2020 will avoid 591 premature global respiratory deaths among the population aged $30+$ due to long-term peak ozone exposure, with a value of (2011) $\$ 1,775 / \mathrm{t}-\mathrm{CH}_{4} .^{12}$

To place these estimates in context, they can be compared to the social cost of methane. Since 2008, US Government Regulatory Impact Analyses have used the Social Cost of Carbon Dioxide (SCC) to estimate the climate change benefits due to a marginal (1 tonne) reduction in carbon dioxide. Standardized values were developed in 2010 (US Department of Energy 2010) and revised in 2013 (US Government 2013). Although the US Government

\footnotetext{
11 As described in Sect. 2, our base estimates for the value of avoided short-term mortality are discounted at a constant $3 \%$ rate, using the MiniCAM GDP and population scenario, average $\Delta \mathrm{O}_{3}$ of 13 ppt annual average, and $\beta$ of $0.64 \%$ per $10 \mathrm{ppb}$ ozone, the IFs baseline mortality projections, and a 0.4 income elasticity for VSL. 12 The base estimate of long-term mortality uses identical parameters to the short-term exposure estimate, with the exception of $\Delta \mathrm{O}_{3}$ and $\beta$, where instead the base estimate relies on the maximum six-month average of the 1-h daily maximum response of $24 \mathrm{ppt}$ per $\mathrm{Tg}$ methane and the concentration-response function is $4 \%$ per $10 \mathrm{ppb}$ ozone, respectively.
} 
does not have a standardized SC- $\mathrm{CH}_{4}$ estimate, recent US EPA Regulations ${ }^{13}$ have included monetized climate benefits from methane emissions reductions. ${ }^{14}$ These estimates of the SC$\mathrm{CH}_{4}$ were based on the current SCC estimate, transformed using the GWP for methane. Using the current $2020 \mathrm{SCC}$ central $^{15}$ value of (2011)\$46 and GWP of 25 yields (2011)\$1,150/t$\mathrm{CH}_{4}$. The $\mathrm{SC}-\mathrm{CH}_{4}$ can also be estimated directly by the models used to estimate the SCC. Waldhoff et al. (2014); (Marten et al. 2014) and Marten and Newbold (2012) both found that the directly modeled relative damage of $\mathrm{CH}_{4}$ to $\mathrm{CO}_{2}$ was greater than the GWP-based damages. ${ }^{16}$ Marten et al. (2014) use a methodology consistent with the US Government SCC and the sensitivities tested in this paper and found that for $\mathrm{CH}_{4}$ emissions in 2020, at a discount rate of $3 \%$, the Social Cost of Methane was (2007)\$1200 (or \$1302 in 2011\$). The global ozone mortality benefits estimated in this paper are 0.7 or 1.5 times the estimate of climate benefits using the updated SCC and GWP, and 0.6 or 1.4 times the estimate of climate benefits from Marten et al. (2014), for the short and long-term ozone mortality estimates, respectively.

\subsection{Sensitivity Analyses}

We tested the sensitivity of the results to a number of parameter assumptions and explored the relative importance of different factors in determining the mortality benefit, as described above. These sensitivities were all calculated relative to the base case. Sensitivity ranges were chosen based on ranges for parameters provided within underlying studies $\left(\Delta \mathrm{O}_{3}, \beta\right.$, Ramsey discount rates), sensitivities used within the US Government SCC approach (discount rates 2.5, 3, and 5\%, different scenarios, emission years), OMB Circular A-4 (discount rate of 7), and reasonable bounding parameters chosen by the authors (VSL elasticities and CVP mortality rate). Therefore, while these calculations are informative, this sensitivity analysis is not comprehensive nor are the ranges as comparable as they would be if they were all equivalent standard deviation ranges.

Figure 1 shows the difference between the base estimate, (2011)\$790/t- $\mathrm{CH}_{4}$, and each sensitivity and Table 1 reports the estimates for each of the alternate measures for the specified parameters. The estimates are very sensitive to the elasticity parameter used to extrapolate the VSL over region and time. The use of a constant VSL $(\varepsilon=0)$ nearly doubles the base estimate in 2020, while the VSL estimated as a strict ratio of per capita income $(\varepsilon=1)$ produces an estimate only half of the base value.

Figure 2 shows the effect of the different VSL metrics on the $\mathrm{CH}_{4}$ mortality benefit over time. The estimate using $\varepsilon=1$ is one-half the base estimate in 2020 and increases to twothirds the base estimate in 2050. Similarly, an elasticity of 0 produces a mortality benefit roughly twice as large as the base estimate in 2020 , but only 1.5 times larger in 2050 . That

13 Federal Register Vol 77. No. 159, 49536, 2012 and Federal Register Vol 77, No. 199, 62930, 2012.

14 Recent rules have relied on the SCC estimates developed in 2010 (central estimate of (2011)\$28/t-CO 2 ) and two different GWP values: the Second Assessment Report GWP of 21 [for consistency with UNFCCC guidelines (Oil and Gas)] and a GWP of 25 [(for consistency with the most recent IPCC report at the time (Light-Duty Vehicle)]. The use of the former results in a $\mathrm{SC}-\mathrm{CH}_{4}$ estimate of (2011)\$585 and the latter in a value of (2011)\$697.

15 Due to many uncertainties in the calculation of the SCC, the US Government provides and uses a range of SCC values. For $\mathrm{CO}_{2}$ emissions in 2020, these values range from (2011)\$13 to $\$ 137$. See http://www.whitehouse.gov/sites/default/files/omb/assets/inforeg/technical-update-social-costof-carbon-for-regulator-impact-analysis.pdf for additional detail.

16 Differences between the GWP and explicit approaches stem mainly from the different temporal valuation methods (combined with the fact that methane has a shorter lifetime than $\mathrm{CO}_{2}$ ), and the inclusion of positive yield effects on agriculture from $\mathrm{CO}_{2}$ fertilization in some of the underlying integrated assessment models. 


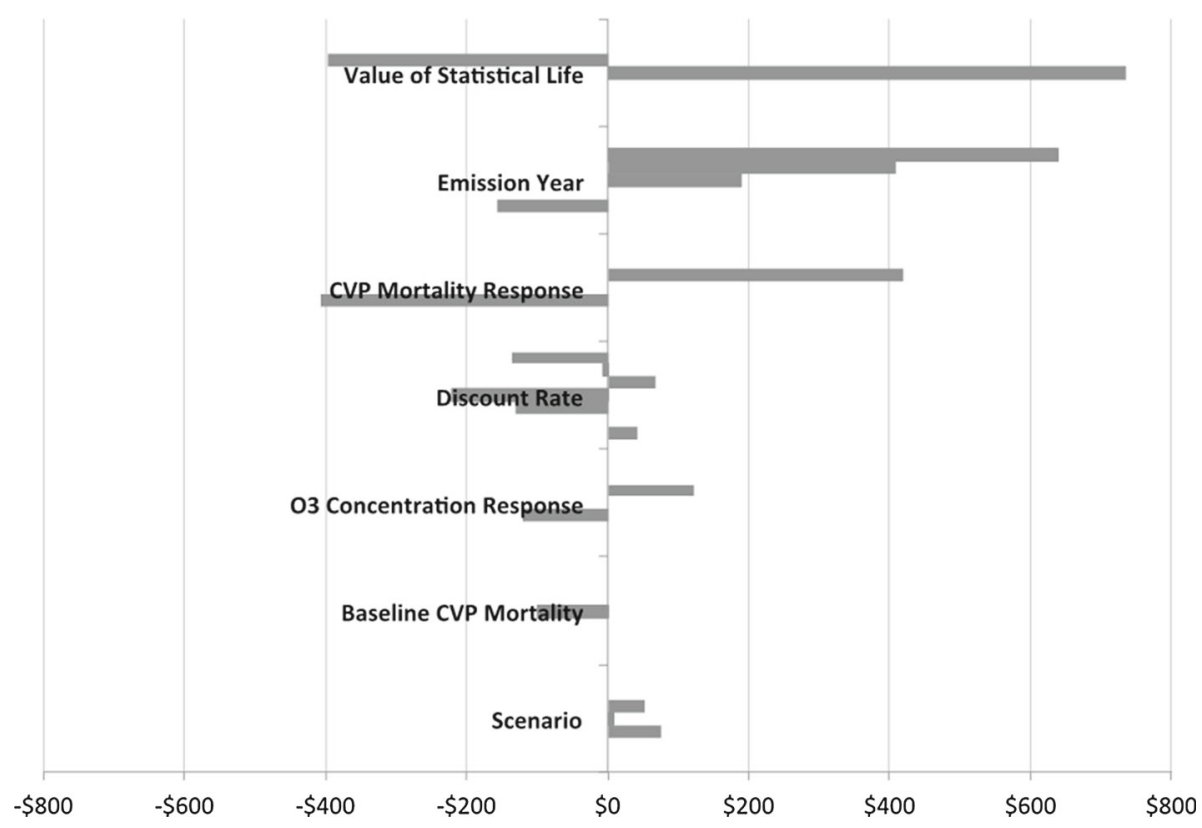

Fig. 1 Differences between the short-term mortality base estimate (2011)\$790/t- $\mathrm{CH}_{4}$ and multiple parameter sensitivities. See Table 1 for a listing of sensitivity runs for each parameter

the estimates using a constant VSL $(\varepsilon=0)$ are much larger than with the base method is not particularly surprising, as the US 2010 per capita income is substantially greater than most regions in the world at present and greater than what some regions reach even by the end of the century in these scenarios.

The year of emission also has a large effect on the estimate, with benefits per tonne more than doubling for methane emitted between 2010 and 2050 (Fig. 2). Within the base set of parameters, this change is due primarily to increases in population and VSL changes due to income growth over the time period.

Reasonable estimates of future CVP mortality rates have a comparably smaller effect on the base case estimate in 2020: under an assumption of constant CVP mortality rates from 2010 to 2120, the benefit per tonne estimate in 2010 is only $6 \%$ lower. By 2050, however, this assumption decreases the estimate by $30 \%$. As shown in Table 1, the 2020 estimate is roughly $12 \%$ lower using a constant mortality rate than under the base assumptions. Given the extreme nature of an assumption of constant CVP mortality rates through 2120 , it is likely that other, more plausible estimations of mortality rates would have a relatively small effect on the methane indirect health benefits.

We test a wide range of discount rates and methods and find that the estimate of the indirect short-term mortality impacts from a tonne of methane emitted in 2020 using a constant $2.5 \%$ discount rate is about 1.3 times the estimate with a constant $5 \%$ discount rate. In contrast, the SCC is very sensitive to the choice of discount rate and methodology; the SCC is nearly 5.5 times greater when discounted at 2.5 versus $5 \%$. However, Waldhoff et al. (2014) show that direct estimates of the $\mathrm{SC}-\mathrm{CH}_{4}$ are also much less sensitive to discounting than the $\mathrm{SCC}$, due to methane's comparatively short atmospheric lifetime and the resulting nearer-term nature of the damages. The ozone-mediated mortality benefits from methane emissions are even less sensitive to discounting. This is likely due to two reasons. First, the inertia of the 


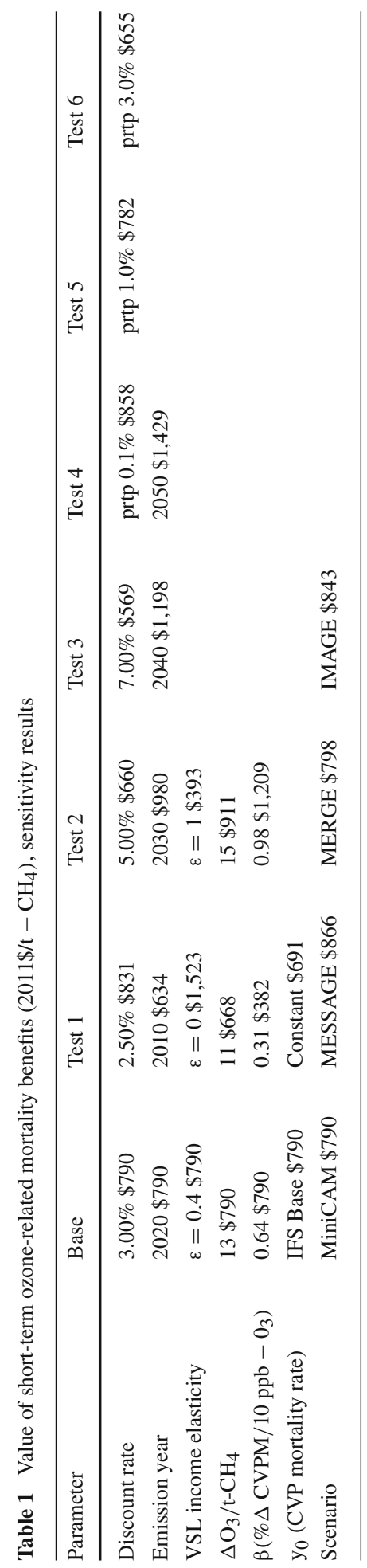




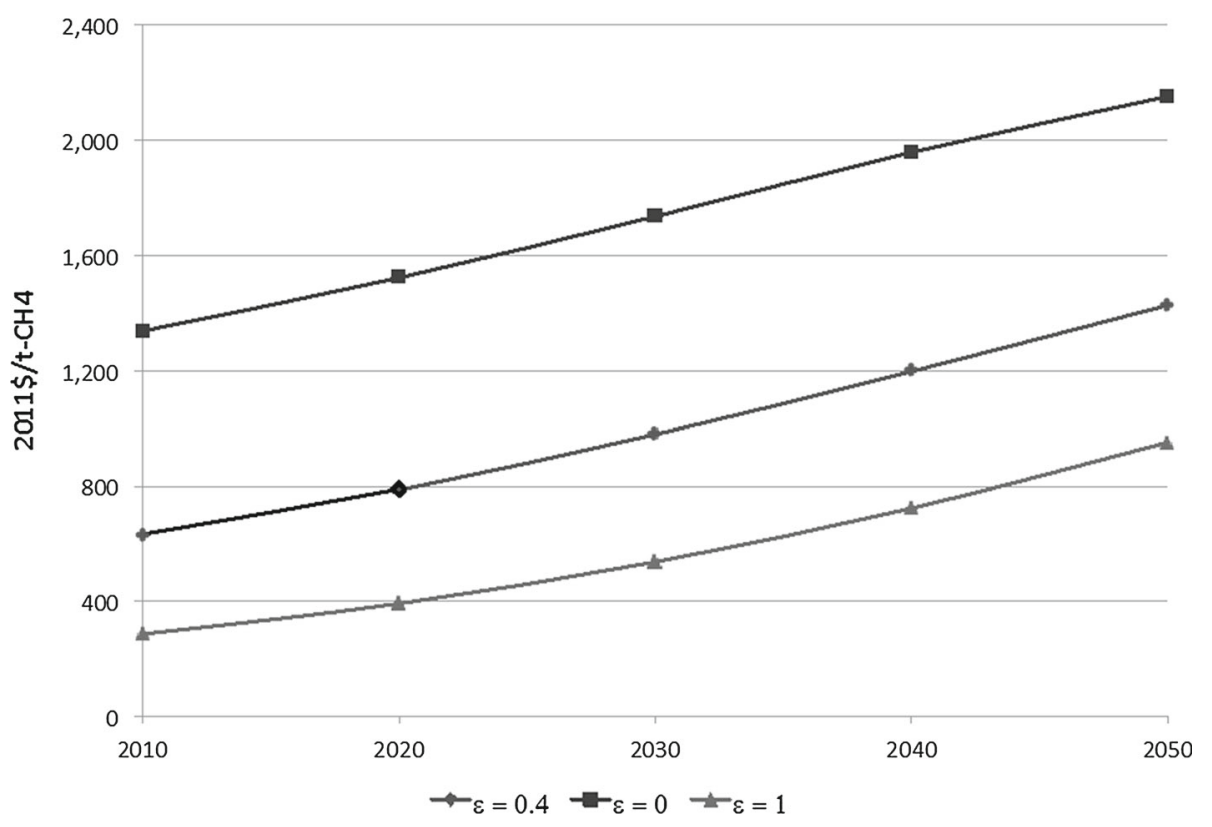

Fig. 2 Sensitivity of short-term ozone-related mortality benefits to VSL and year of emission

climate system will cause temperature changes that last longer than concentration changes and therefore the climate damages, but not the ozone-mediated mortality damages, will continue to increase with future temperature changes. Second, the social cost of methane is a function of the reference temperature as well as population and GDP. Because temperature is increasing in the reference scenarios (even without the addition of a marginal tonne of $\mathrm{CH}_{4}$ ), the climate damages from future climate changes are larger than they would be under present temperature conditions so the climate damages decay slightly more slowly than the mortality damages that are not dependent on temperature.

We examine four different future socio-economic scenarios, namely reference scenarios from the EMF 22 exercise from the IMAGE, MERGE, MESSAGE, and MiniCAM models. The use of different socioeconomic scenarios can increase the base estimate from up to $6 \%$ in 2010 to up to $12 \%$ for emissions in 2050 . The increasing sensitivity across scenarios over time is a result of the growing differences across the models' projections of GDP and population as the scenarios extend into the latter part of this century.

We also examine the sensitivity of incidence results to year of emission, CVP mortality response, $\mathrm{O}_{3}$ concentration-response factor, $\mathrm{CVP}$ mortality rates, and socioeconomic scenario (Figure 3).

The concentration-response factor $(\beta)$ and the year of emission reduction have the largest effect on avoided premature mortality. The 95th percentile ranges of $\beta$ bound the avoided premature mortality between 116 and 366. Over time, a reduction of $1 \mathrm{MMT}-\mathrm{CH}_{4}$ in a single year increases the total avoided deaths, from 210 in 2010 to 329 in 2050.

To put these values in perspective, the recent EPA Oil and Natural Gas Sector: New Source Performance Standards and National Emission Standards for Hazardous Air Pollutants Reviews rule ${ }^{17}$ estimated that actions to reduce VOC emissions from oil and gas production would also reduce methane emissions by 1.0 million tonnes annually, with an

1740 CFR Parts 60 and 63. 


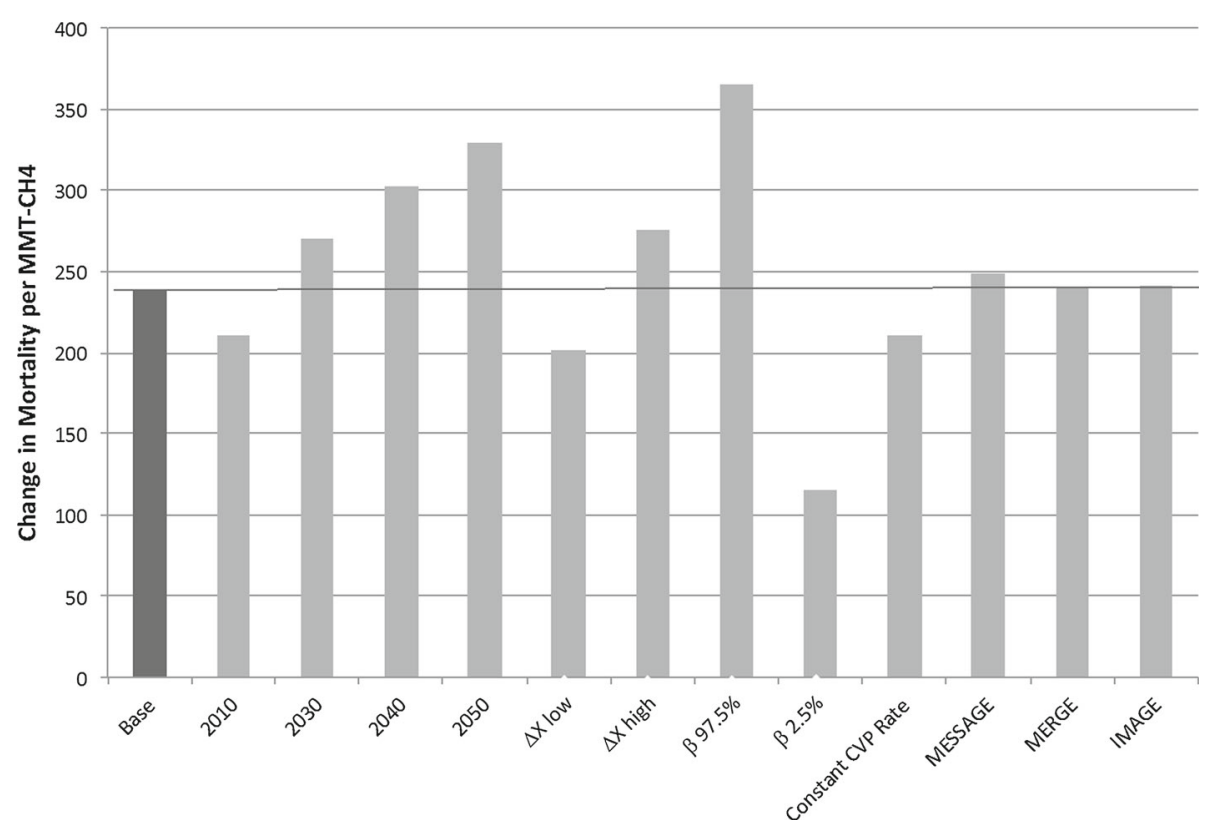

Fig. 3 Avoided short-term ozone-related mortality per $\mathrm{MMT}-\mathrm{CH}_{4}$ reduction, sensitivity results

additional 0.7 million tonnes attributed to voluntary reductions. The net effect of these reduced $\mathrm{CH}_{4}$ emissions in the year 2020 is to avoid 406 premature deaths globally from the resulting reduction in ozone concentrations over the following 70 years. The net present value of the avoided deaths due to reductions in $2020 \mathrm{CH}_{4}$ emissions is $\$ 1.3$ billion using our base estimate.

\subsection{Regional Estimates of Cardiovascular and Pulmonary Mortality Damages}

In order to examine the distributional impacts of methane on ozone health, we present estimates of avoided mortality and benefits by region. As seen in Fig. 4, the estimates vary greatly across regions, ranging from a low of $\$ 44 / \mathrm{t}-\mathrm{CH}_{4}$ in Africa and the Middle East to a high of $\$ 181 / \mathrm{t}-\mathrm{CH}_{4}$ in East Asia under base assumptions. That the US falls somewhat in the middle of this range may seem somewhat surprising. However, the estimates are dependent not only on the VSL within a region, but also on the total population and the baseline cardiovascular and pulmonary death rates. Large populations and high cardiovascular and pulmonary mortality may cause the total benefits to exceed those in regions with much higher per capita incomes. This is demonstrated in Table 2: a one million tonne decrease in emissions in 2020 avoids 12 deaths in the United States, compared to 68 avoided deaths in East Asia. The effects of per capita income (the basis for the VSL estimates) are worth noting, however. While only $4.5 \%$ of the world's population lives in the United States, $10.6 \%$ of the benefits are accrued there, primarily due to differences in the estimated VSL.

As with the global values, the benefits accrued by individual regions is very sensitive to the VSL methodology, though the magnitude, and even sign, varies across regions. When VSL is a constant value $(\varepsilon=0)$, the US value is roughly $5 \%$ of the global estimate. In sharp contrast, a VSL estimate that varies linearly with per capita income $(\varepsilon=1)$ increases the fraction of benefits that accrue in the US to $25 \%$. The effect is opposite to the effects of VSL 


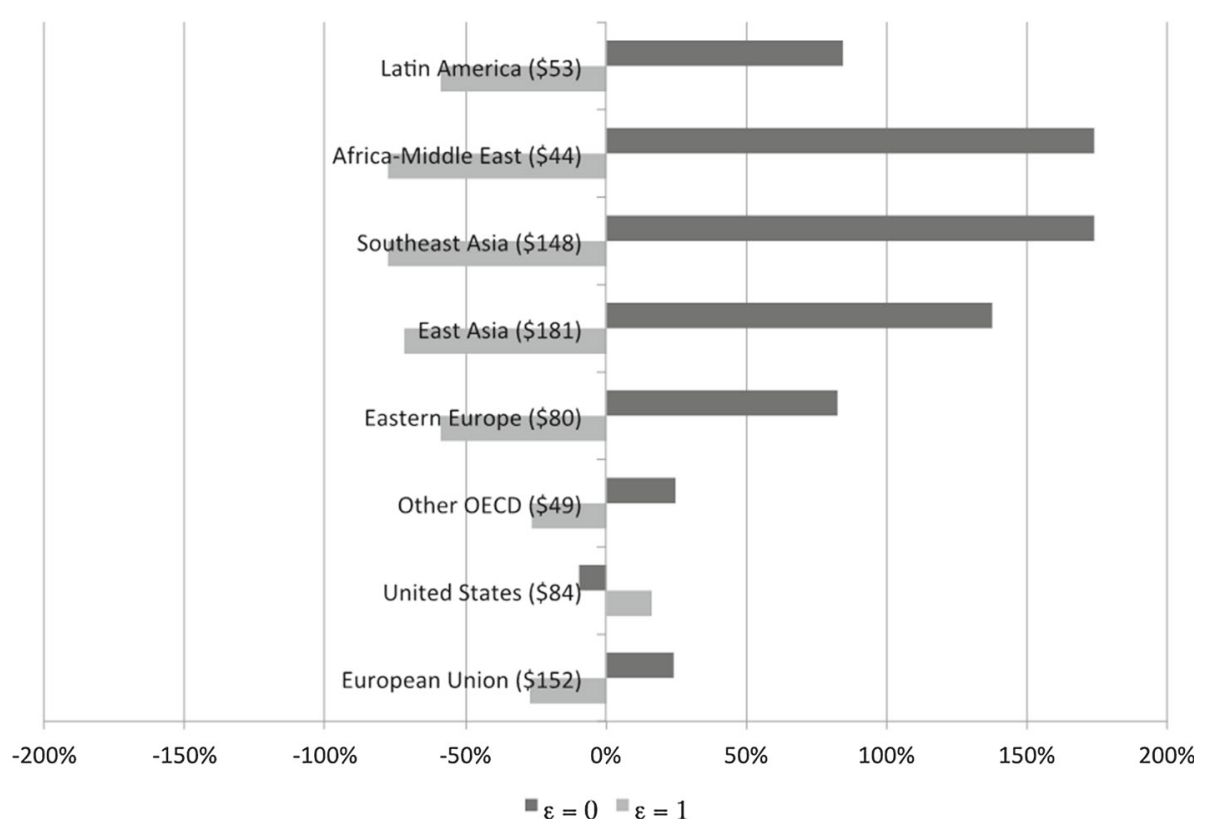

Fig. 4 Percent difference in short-term ozone-related mortality results using a VSL elasticity of $\eta=0.4$, by region (base estimates in parentheses)

Table 2 Total avoided mortality per 1 MMT decrease in $\mathrm{CH}_{4}$ in a given year (base case)

Due to rounding, global totals may not equal the sums of regional values

\begin{tabular}{lrrrrr}
\hline Year & 2010 & 2020 & 2030 & 2040 & 2050 \\
\hline European Union & 26 & 29 & 30 & 32 & 31 \\
United States & 10 & 12 & 14 & 16 & 17 \\
Other OECD & 8 & 10 & 12 & 13 & 14 \\
Eastern Europe & 21 & 23 & 25 & 27 & 29 \\
East Asia & 56 & 68 & 81 & 93 & 102 \\
Southeast Asia & 57 & 64 & 73 & 83 & 93 \\
Africa-Middle East & 19 & 18 & 18 & 18 & 19 \\
Latin America & 13 & 16 & 18 & 21 & 24 \\
Global & 210 & 239 & 271 & 302 & 329 \\
\hline
\end{tabular}

methodology on all other regions, where the use of a constant $(\varepsilon=0)$ VSL increases benefits and the linear method $(\varepsilon=1)$ decreases benefits compared to the base assumption of $\varepsilon=0.4$. This is because the US has a relatively high VSL compared with other regions, particularly in the near-term. A constant 2010 US VSL raises other regions' VSLs by more than it decreases the US value over time. When $\varepsilon=1$, however, the US VSL increases linearly, rather than exponentially at 0.4 . Since other regions have lower incomes, the exponent $(\varepsilon=0.4)$ increases VSL relatively more, and future increases in income in the US do not change the VSL as much as with a $\varepsilon=1$ method.

Further differences can be seen across the magnitude of response to VSL methodology by region (Fig. 4). The use of a constant VSL across region and time has the largest effect on the Africa-Middle East and Southeast Asia regions, increasing the benefits in each region 
nearly $175 \%$ compared to the base estimate. Generally, regions with relatively low per capita incomes have much larger increases in benefits when $\varepsilon=0$ than corresponding decrease when $\varepsilon=1$. Higher income regions (e.g. European Union and Other OECD) have comparable changes between the two methods.

For further comparison, Table 2 shows the total avoided deaths for a one million tonne decrease in methane emissions in each year. While economic growth, across regions and over time, has a large effect on the monetized benefits, the drivers of avoided mortality are population and baseline mortality rates, both of which vary by region and over time.

Total avoided deaths for $1 \mathrm{MMT}-\mathrm{CH}_{4}$ emissions reduction increases over time most rapidly for three regions: Other OECD, East Asia, and Latin America, all seeing avoided mortalities increase by more than $80 \%$ between 2010 and 2050. These increases are driven primarily by rapidly increasing cardiovascular and pulmonary death rates. Similarly, the Africa and Middle East region shows practically no change in total avoided mortality over time. This is because the increase in population in this region is almost perfectly offset by the decrease in cardiovascular and pulmonary death rates through mid-century. ${ }^{18}$ This region begins the century with the lowest cardiovascular and pulmonary death rates, and though these rates are projected to begin increasing again around 2050, by century's end the rate is still lower than in 2010.

\subsection{Long-Term Ozone Mortality and Damages}

In addition to cardiovascular and pulmonary mortality from short-term exposure to peak ozone concentrations, changes in methane emissions can also impact respiratory mortality from long-term exposure to average ozone concentrations. We examine the mortality effects and damages of chronic ozone exposure due to changes in methane emissions and test the sensitivity of the results to several parameters. While the long-term mortality results respond similarly to the short-term estimates for most of the sensitivity tests, there are two differences worth noting. The long-term concentration-response factor has a relatively large $95 \%$ confidence interval. Because of this, the long-term respiratory mortality results are very sensitive to this parameter, with a range of (2011)\$444-\$2973.

Additionally, as seen in Fig. 5, the benefits of avoided respiratory morality due to long-term ozone exposure increase over time at a faster rate than for the avoided cardiovascular and pulmonary mortality due to short-term ozone exposure. The long-term benefits per tonne of $\mathrm{CH}_{4}$ mitigated increase from $\$ 1301$ in 2010 to $\$ 3846$ in 2050, while the short-term benefits increase from $\$ 634$ to $\$ 1,428$ in the same period. The primary reason for the faster increase in benefits is that the long-term mortality impacts are based only on the sub-set of the population ages 30 and above. Globally, the affected demographic (population 30+) for the long-term impacts is growing faster than the total population, upon which the short-term estimates are based.

The long-term mortality relationships include both acute and chronic effects of ozone exposure, so the significantly larger long-term mortality estimates suggest that considering only short-term mortality may exclude a substantial portion of ozone-related risk. However, because the short-term mortality relationships include a larger population (all ages versus adults ages 30 and older only) and mortality due to any cardiovascular and pulmonary disease

\footnotetext{
18 Although well beyond the scope of this paper to examine in detail, if other causes of mortality, such as communicable diseases and conflict-related deaths, were to decrease significantly through the century, the region would see a commensurate increase in cardiovascular-pulmonary mortality and total population, thus increasing total benefits and avoided premature deaths. So although sensitivity with respect to baseline mortality rates is tested, using constant rates over time, changes in other underlying trends in mortality causes and rates may impact these results.
} 




Fig. 5 Global short-term and long-term health benefits per tonne- $\mathrm{CH}_{4}, 2010-2050$

rather than just respiratory disease, the short-term mortality estimates may include some ozone mortality effects that are not captured in the long-term results. As the extent of the overlap between these estimates is unknown, the short-term and long-term mortality results should be viewed as complementary estimates, rather than additive or one as a subset of the other.

These results can be compared to work by (Shindell et al. 2012) that shows long-term global methane health benefit estimates in the range of $\$ 1080 \pm \$ 721 / \mathrm{t}-\mathrm{CH}_{4}$ (in 2006\$). ${ }^{19}$ There are several of differences between the Shindell et al. approach and the methods used in this paper. The key difference is that the estimates presented in this paper follow the decay of a pulse of methane over a period of time and reflect the value of the change in mortality due to the resulting ozone concentration to the population in the same time period. For a pulse of methane emitted in 2020, the ozone increment in 2020 is applied to the population in 2020, the ozone increment in 2021 is applied to the population in 2021, and so forth, and the changes in mortality in each region and year are valued with a region and time consistent with estimated VSL. In contrast, Shindell et al. used a more sophisticated chemistry-climate model to calculate the ozone changes driven by emission changes in 2030 and averaging the ozone response in years 30-50 of the simulation. This ozone increment is then applied to the population of 2030 in order to estimate changes in mortality. The Shindell et al. approach would be expected to yield a result more similar to the integrated valuation of a single year's emissions (as in this paper) with no future changes in population, GDP, or mortality response, and if future benefits were not discounted. In addition, Shindell et al. include $\mathrm{PM}_{2.5}$ concentration changes and health impacts resulting from $\mathrm{CH}_{4}$ emission reductions, whereas we focus here on ozone only.

19 Or roughly (2011)\$1186 $\pm \$ 792$, when converted using a GDP deflator of 1.098 . 


\subsection{Caveats and Limitations}

A few of the assumptions made to develop these benefits estimates have the potential to slightly increase the range of possible outcomes. For simplicity these estimates assume that the ozone concentration response to methane is homogenous. However, (Anenberg et al. 2012) suggest accounting for the heterogeneity in ozone response to $\mathrm{CH}_{4}$ may lead to differences in mortality estimation on the order of $15 \%$ globally, with uncertain sign. The decay rate of methane is also not a constant, with some papers suggesting that it might change by up to $10 \%$ depending on emissions of VOCs, $\mathrm{NO}_{X}$, and methane itself (Sarofim 2012). A change in the overall decay rate would presumably also have an effect on the rate of ozone production. However, these effects are relatively small compared to the uncertainties involved in the choices of VSL and discount rates considered above.

Due to lack of regional studies, we also apply concentration-response functions found in the US globally, though differences in exposure and population susceptibility characteristics (e.g. time spent outdoors, home ventilation rates, medical care, etc.) could cause differences in this factor across regions. As discussed in Anenberg et al. (2010), short-term $\mathrm{O}_{3}$ epidemiology studies in developing nations produce fairly similar results to short-term studies in North America and Europe (Health Effects Institute International Scientific Oversight Committee 2004). Furthermore, concentration-mortality relationships do not vary significantly by sex, age, and race (Jerrett et al. 2009; Krewski et al. 2009; Zanobetti et al. 2000), although some sensitive populations may be at a higher risk. We base our estimates on cardiovascular and respiratory mortality rates rather than all-cause mortality rates because this will reduce errors due to differences in causes of deaths across regions.

These estimates also do not include the benefits of avoided morbidity. The additional value of reduced morbidity from reductions in ozone concentrations due to lower methane emissions would likely increase the total health benefit valuation, though precisely how much is left to future work. Additional effects that would serve as a complement to both the climate effects from the social cost of methane and the health effects from this analysis include the effect of ozone concentrations on agricultural and forestry yields (Avnery et al. 2013) and on the carbon uptake of natural systems (Feltzer et al. 2005).

One effect that could lead to our results being overestimates is our exclusion of particulate matter concentrations and health impacts. Reduced methane emissions may affect atmospheric oxidant concentrations, leading to increased production of sulfate, a component of particulate matter pollution (Anenberg et al. 2012). Increased particulate matter-related health impacts resulting from reduced methane emissions may counteract some of the ozonerelated health benefits.

\section{Conclusions and Future Directions}

This paper estimates the premature mortality benefits of reducing ozone concentrations through reductions in methane emissions. This estimate is the first one that is consistent methodologically with the approach used in estimating the social cost of carbon values used by the US Government for regulatory analyses. This paper also examines the sensitivity of the estimates to several key parameters and methodologies. We estimate that a one million tonne decrease in methane emissions in 2020 will avoid 239 premature cardiovascular and pulmonary deaths globally due to short-term peak ozone exposure and 591 premature respiratory deaths globally due to long-term peak ozone exposure. The values of these mortality benefits are (2011)\$790/t- $\mathrm{CH}_{4}$ and $\$ 1,775 / \mathrm{t}-\mathrm{CH}_{4}$, respectively. Ozone mortality benefits are 
0.7-1.5 times the estimate of climate benefits based on the US Government's central SCC estimate and GWP, or 0.6-0.4 times the estimate of climate benefits based on Marten et al. (2014), with the range depending on whether the short or long-term ozone mortality estimate is used. Both measures are uncertain. With the sensitivities examined here, the highest estimate of the short-term health benefits is four times greater than the lowest. Including the benefits estimates of long-term ozone exposure-related mortality increases the upper bound of the range even further. The climate benefits of $\mathrm{CH}_{4}$ emissions reductions, as measured by the $\mathrm{SC}-\mathrm{CH}_{4}$ (calculated using the US Government's SCC estimates and the $\mathrm{CH}_{4} \mathrm{GWP}$ ), span a range of 10 times the lowest to the highest estimate. ${ }^{20}$

Significant differences in avoided mortality and monetized benefits exist across regions. Differences in the number of avoided premature deaths are due to regional populations, growth rates, and baseline cardiovascular and pulmonary death rates. While the monetized damages are partially dependent upon the number of avoided premature deaths in a region, the method used for the extrapolation of the VSL across regions and time has a very large impact on the estimated monetized benefits; in some regions it has the potential to increase monetized benefits by more than 10 times.

We find that the benefits of avoided cardiovascular and pulmonary mortality due to reductions in methane emissions are substantial and are an important benefit to include when assessing the benefits of methane mitigation policies.

Acknowledgements The authors would like to thank Neal Fann, Amy Lamson, Bryan Hubbell, Jason West, and Steve Smith for reviews and comments on drafts of this paper. Stephanie Waldhoff gratefully acknowledges the U.S. Environmental Protection Agency for support of this work. Susan Anenberg performed the work on this paper while employed by the U.S. Environmental Protection Agency. The views expressed in this paper are those of the authors and do not reflect those of the U.S. Environmental Protection Agency, Pacific Northwest National Laboratory, nor the U.S. Department of Energy.

Open Access This article is distributed under the terms of the Creative Commons Attribution 4.0 International License (http://creativecommons.org/licenses/by/4.0/), which permits unrestricted use, distribution, and reproduction in any medium, provided you give appropriate credit to the original author(s) and the source, provide a link to the Creative Commons license, and indicate if changes were made.

\section{References}

Anenberg SC, Horowitz LW, Tong DQ, West JJ (2010) An estimate of the global burden of anthropogenic ozone and fine particulate matter on premature human mortality using atmospheric modeling. Environ Health Perspect 118(9):1189-1195. doi:10.1289/ehp.0901220

Anenberg SC, Schwartz J, Shindell D, Amann M, Faluvegi G, Klimont Z (2012) Global air quality and health co-benefits of mitigating near-term climate change through methane and black carbon emission controls. Environ Health Perspect 120(6):831. doi:10.1289/ehp.1104301

Anenberg SC, West JJ, Fiore AM, Jaffe DA, Prather MJ, Bergmann D, Zeng G (2009) Intercontinental impacts of ozone pollution on human mortality. Environ Sci Technol 43(17):6482-6487. doi:10.1021/es900518z

Anthoff D, Tol RSJ (2013) The uncertainty about the social cost of carbon: a decomposition analysis using fund. Clim Change 117(3):515-530. doi:10.1007/s10584-013-0706-7

Avnery S, Mauzerall DL, Fiore AM (2013) Increasing global agricultural production by reducing ozone damages via methane emission controls and ozone-resistant cultivar selection. Glob Change Biol 19. doi: $10.1111 / \mathrm{gcb} .12118$

Bell ML, McDermott A, Zeger SL, Samet JM, Dominici F (2004) Ozone and short-term mortality in 95 US urban communities, 1987-2000. JAMA J Am Med Assoc 292(19):2372-2378

20 There are many additional factors that increase the range of $\mathrm{SC}-\mathrm{CH}_{4}$ estimates. For instance, climate sensitivity has a large effect on the results, the office US Government SCC estimates are based on the results of three models, and the differences between methods used to calculate the $\mathrm{SC}-\mathrm{CH}_{4}$ (conversion of the SCC with GWP vs. direct estimation). 
Clarke L, Edmonds J, Krey V, Richels R, Rose S, Tavoni M (2009) International climate policy architectures: overview of the EMF 22 international scenarios. Energy Econ 31(Supplement 2):S64-S81. doi:10.1016/ j.eneco.2009.10.013

Feltzer B, Reilly K, Melillo J, Kighlighter D, Sarofim M, Wang C et al (2005) Future effects of ozone on carbon sequestration and climate change policy using a global biogeochemical model. Clim Change 73(3):28

Fiore AM, West JJ, Horowitz LW, Naik V, Schwarzkopf MD (2008) Characterizing the tropospheric ozone response to methane emission controls and the benefits to climate and air quality. J Geophys Res Atmos (1984-2012) 113 (D8). doi:10.1029/2007JD009162

Hammitt J, Robinson L (2011) The income elasticity of the value per statistical life: transferring estimates between high and low income countries. J Benefit Cost Anal 2(1):1-29

Health Effects Institute International Scientific Oversight Committee (2004) Health effects of outdoor air pollution in developing countries of Asia: a literature review. Health Effects Institute, Boston

International Futures (2013) The international futures (IFs) modeling system, Version 6.69 [Pardee FS, Center for International Futures, Josef Korbel School of International Studies, University of Denver, Denver, $\mathrm{CO}]$

IPCC (2007) Climate change 2007: the physical science basis. Contribution of working group I to the fourth assessment report of the intergovernmental panel on climate change [Solomon S, Qin D, Manning M, Chen Z, Marquis M, Averyt KB, Tignor M, Miller HL (eds)]. Cambridge University Press, Cambridge, UK and New York, USA, 996 pp

IPCC (2013) Climate change 2013: the physical science basis. Contribution of working group I to the fifth assessment report of the intergovernmental panel on climate change [Stocker TF, Qin D, Plattner GK, Tignor M, Allen SK, Boschung J, Nauels A, Xia Y, Bex V, Midgley PM (eds)]. Cambridge University Press, Cambridge, UK and New York, USA, 1535 pp

Jerrett M, Burnett RT, Pope CA III, Ito K, Thurston G, Krewski D, Thun M (2009) Long-term ozone exposure and mortality. New Engl J Med 360(11):1085-1095. doi:10.1056/NEJMoa0803894

Krewski D, Jerrett M, Burnett R, Ma R, Hughes E, Shi Y et al (2009) Extended follow-up and spatial analysis of the American cancer society study linking particulate air pollution and mortality. Health Effects Institute, Boston

Lim SS, Vos T, Flaxman AD, Danaei G, Shibuya K, Adair-Rohani H, Ezzati M (2012) A comparative risk assessment of burden of disease and injury attributable to 67 risk factors and risk factor clusters in 21 regions, 1990-2010: a systematic analysis for the global burden of disease study 2010. Lancet 380(9859):2224-2260

Marten AL, Newbold SC (2012) Estimating the social cost of non-CO2 GHG emissions: methane and nitrous oxide. Energy Policy 51:957-972. doi:10.1016/j.enpol.2012.09.073

Mathers CD, Fat DM, Boerma J (2008) The global burden of disease: 2004 update. World Health Organization, Geneva

Marten AL, Kopits EA, Griffiths CW, Newbold SC, Wolverton A (2014) Incremental CH4 and N2O mitigation benefits consistent with the US Government's SC-CO2 estimates. Clim Policy:1-27. doi:10.1080/ 14693062.2014.912981

Nakicenovic N (2000) Special report on emissions scenarios : a special report of working group III of the intergovernmental panel on climate change. Intergovernmental Panel on Climate Change Working Group III, Cambridge

Sarofim M (2012) The GTP of methane: modeling analysis of temperature impacts of methane and carbon dioxide reductions. Environmental Model Assessment. doi:10.1007/s10666-011-9287-x

Shindell D, Kuylenstierna JCI, Vignati E, van Dingenen R, Amann M, Klimont Z, Fowler D (2012) Simultaneously mitigating near-term climate change and improving human health and food security. Science 335(6065):183-189. doi:10.1126/science. 1210026

United Nations (2004) World Population To 2300 (trans: Department of Economic and Social Affairs PD). United Nations, New York

US Department of Energy (2010) Energy conservation program: energy conservation standards for small electric motors, Final Rule. vol 75. Federal Register

US Environmental Protection Agency (2010) Guidelines for preparing economic analyses. http://yosemite. epa.gov/ee/epa/eerm.nsf/vwAN/EE-0568-50.pdf

US Environmental Protection Agency (2012) Integrated science assessment for ozone and related photochemical oxidants: third external review draft

US Government (2013) Technical support document: technical update of the social cost of carbon for regulatory impact analysis - under executive order vol 12866. http://www.whitehouse.gov/sites/default/files/omb/ inforeg/for-agencies/Social-Cost-of-Carbon-for-RIA.pdf

US Office of Management and Budget (2003) Circular A-4: regulatory analysis. http://www.whitehouse.gov/ sites/default/files/omb/assets/regulatory_matters_pdf/a-4.pdf 
Waldhoff ST, Anthoff D, Rose SK, Tol RSJ (2014) The marginal damage costs of different greenhouse gases: An application of FUND. Open Access Open Assess E J Econ. doi:10.5018/economics-ejournal.ja. 2014-31

West JJ, Fiore AM, Horowitz LW, Mauzerall DL (2006) Global health benefits of mitigating ozone pollution with methane emission controls. Proc Natl Acad Sci USA 103(11):3988-3993. doi:10.1073/pnas. 0600201103

Zanobetti A, Schwartz J, Gold D (2000) Are there sensitive subgroups for the effects of airborne particles? Environ Health Perspect 108:5 